\title{
Randomized phase II study of TJ-54 (Yokukansan) for postoperative delirium in gastrointestinal and lung malignancy patients
}

\author{
NOBUHIRO SUGANO $^{1 *}$, TORU AOYAMA ${ }^{1 *}$, TSUTOMU SATO ${ }^{1}$, MARIKO KAMIYA $^{1}$, SHINYA AMANO $^{1}$, \\ NAOTO YAMAMOTO ${ }^{1}$, TAKUYA NAGASHIMA ${ }^{1}$, YOSHIHIRO ISHIKAWA ${ }^{1}$, KATSUHIKO MASUDO ${ }^{1}$, \\ MASATAKA TAGURI ${ }^{2}$, TAKEHARU YAMANAKA ${ }^{2}$, YUJI YAMAMOTO ${ }^{1}$, HIROSHI MATSUKAWA ${ }^{1}$, \\ RYUJI SHIRAISI ${ }^{1}$, TAKASHI OSHIMA ${ }^{1}$, NORIO YUKAWA ${ }^{1}$, YASUSHI RINO ${ }^{1}$ and MUNETAKA MASUDA ${ }^{1}$
}

Departments of ${ }^{1}$ Surgery and ${ }^{2}$ Biostatistics, Yokohama City University, Yokohama 236-0004, Japan

Received March 22, 2017; Accepted July 22, 2017

DOI: $10.3892 / \operatorname{mco} .2017 .1357$

\begin{abstract}
The present study evaluated the efficacy and safety of TJ-54 (Yokukansan; a traditional Japanese medicine) for the prevention and/or treatment of postoperative delirium in a randomized phase II trial of patients receiving surgery for gastrointestinal and lung malignancies. Patients $\geq 70$ years of age who underwent surgery for gastrointestinal or lung malignancy were eligible for participation in the study. The 186 eligible patients were randomly assigned at a 1:1 ratio to receive TJ-54 or control during their peri-operative care (between 7 days prior to surgery and 4 days following surgery, except for the operation day). The signs and symptoms of delirium were assessed using the Diagnostic and Statistical Manual of Mental Disorders-IV by the investigator during the peri-operative period. A total of 186 eligible gastrointestinal or lung malignancy patients were analyzed (93, TJ-54; 93, control). There were no marked differences between the two randomized groups. The incidence of delirium was $6.5 \%$ (6 patients) in the TJ-54 group and 9.7\% (9 patients) in the control group, with no significant difference $(\mathrm{P}=0.419)$. However, of the patients categorized with a mini-mental state examination (MMSE) score of $\leq 26$, the incidence of postoperative delirium was $9.1 \%$ in the TJ-54 group and $26.9 \%$ in the control group [risk ratio, $0.338 ; 95 \%$ confidence interval (0.078-1.462), $\mathrm{P}=0.115]$. Treatment with TJ-54 reduced the incidence of postoperative delirium compared with the control group. Although TJ-54 did not demonstrate any contribution to preventing or treating postoperative delirium in patients
\end{abstract}

Correspondence to: Dr Toru Aoyama, Department of Surgery, Yokohama City University, 3-9 Fukuura, Kanazawa-ku, Yokohama 236-0004, Japan

E-mail: t-aoyama@lilac.plala.or.jp

${ }^{*}$ Contributed equally

Key words: Yokukansan, postoperative delirium, gastrointestinal cancer, lung cancer following surgery for gastrointestinal or lung malignancy, TJ-54 reduced the risk of postoperative delirium in the patients who were classified as MMSE $\leq 26$. Further phase III studies with a larger sample size are required in order to clarify the effects of TJ-54 against postoperative delirium.

\section{Introduction}

An estimated 14.1 million new cancer cases and 8.2 million cancer deaths occurred in 2012 worldwide (1). Surgical resection is one of the major methods of treating cancer. However, the morbidity after surgery has been reported to range from 20 to $65 \%$ (2-4). Delirium is a particularly common morbidity after surgery (5). Postoperative delirium makes patient management much more difficult, increases costs, and causes severe discomfort to the patient $(6,7)$. Delirium is also associated with increased postoperative mortality and morbidity and with delayed functional recovery $(8,9)$. Although a range of interventions have been developed to prevent and treat postoperative delirium, a more rational approach is necessary.

Yokukansan (TJ-54) is a traditional Japanese herbal medicine (Kampo; granules) extracted from seven medicinal herbs (Atractylodes lancea rhizome, Poria sclerotium, Cnidium rhizome, Uncaria hook, Japanese angelica root, Bupleurum root and Glycyrrhiza). Originally used to treat neurosis, insomnia and irritability and/or agitation in infants, TJ-54 has been approved in Japan as a prescription drug (10). The mechanisms of action of TJ-54 are as follows: i) Partial agonistic effects for 5-HT 1A receptors, ii) antagonistic effects for 5-HT 2A receptors and iii) protective effects against glutamate-induced excitatory neurotoxicity by amelioration of astrocyte dysfunction (11-15). Recently, Arai et al found that TJ-54 alleviated preoperative anxiety without undesirable sedation when compared with diazepam (16).

Given these previous clinical and biochemical study findings, in the present study, the efficacy of TJ-54 in the prevention and/or treatment of delirium was investigated in a randomized phase II clinical trial in the patients receiving surgery for gastrointestinal or lung malignancy. 


\section{Materials and methods}

Study design. A prospective, multi-institutional, randomized, phase II trial was performed in patients receiving surgery for gastrointestinal or lung malignancy in Japan. The eligible patients were centrally randomized to receive either TJ-54 or control during their perioperative care (between day 7 before surgery to day 4 after surgery, excluding the operation day). The patients were stratified according to gender, performance status before surgery, type of malignancies and institution before randomization at a 1:1 ratio.

The primary aim of the present study was to determine the efficacy and safety of TJ-54 compared with the control group. The primary endpoint was the incidence of delirium after surgery and safety. The secondary endpoints were the length of the hospital stay.

Ethics. The study data and informed consent were obtained in accordance with the Declaration of Helsinki, and the study protocol was approved by the Ethics Review Board of each institution (nine institutions participated the present study. The details were as follows: Miura City Hospital, Japanese Red Cross Hadano Hospital, International University of Health and Welfare Atami Hospital, Kanagawa Prefectural Ashigarakami Hospital, Yokohama Minami Kyosai Hospital, Hiratsuka Kyosai Hospital, Fujisawa Shonandai Hospital, Yokohama Kamishirane Hospital and Yokohama City University). All the patients were given a written explanation of the study protocol and they all provided their written informed consent before participating. This trial was registered in the University Hospital Medical Information Network (UMIN) center (ID UMIN000005423).

Inclusion and exclusion criteria. Patients $\geq 70$ years of age who underwent surgery for gastrointestinal or lung malignancies were considered eligible for this study. All the participants were required to have an Eastern Cooperative Oncology Group performance status $\leq 2$; to receive a mini-mental state examination (MMSE) before enrollment and to have an adequate hepatic, renal, and bone marrow function [white blood cell (WBC) count $\geq 3,000 / \mathrm{mm}^{3}$ and $\leq 12,000 / \mathrm{mm}^{3}$, platelet count $\geq 75,000 / \mathrm{mm}^{3}$, GOT and GPT $\leq 100 \mathrm{U} / 1$, total bilirubin $<1.5 \mathrm{mg} / \mathrm{dl}$, and creatinine $<1.5 \mathrm{mg} / \mathrm{dl}$. Patients with any of the following characteristics were not eligible for the study: A history of severe hypersensitivity (allergy) to any medicine containing antiphlogistic, analgesics, opioids or steroids. Patients with serious constipation or who were pregnant or lactating were excluded from the study. Other medical conditions that rendered a patient unsuitable for inclusion in the study according to the opinion of the investigator were also considered to be exclusion criteria for this study.

Study drug. The study medication Yokukansan [Tsumura Yokukansan Extract Granules for Ethical Use; TJ-54 (Tsumura, Japan)] was administered 3 times a day (2.5 g each time, $7.5 \mathrm{~g} / \mathrm{day})$. The amount of TJ-54 could be decreased depending on the participant's condition or adverse reactions.

Study assessment. The signs and symptoms of delirium were assessed by the investigator during the perioperative period.
The Diagnostic and Statistical Manual of Mental Disorders (DSM)-IV was used to assess delirium (17). Delirium was independently evaluated by two physicians who were previously trained on the algorithm. The time to healing of delirium was defined as the period from the date of onset of delirium to the date when the delirium symptoms disappeared. If the delirium symptoms failed to disappear within the study treatment period, observation was continued until symptom disappearance. Safety was assessed throughout the study using physical examinations, hematology and serum chemistry laboratory tests and adverse event reporting. Any adverse event, whether related or unrelated to the study drug, was reported with the date and time of onset, severity, pattern, action taken and outcome. If the adverse event was not resolved at the time the case report forms were collected, a follow-up report was provided at a later date. If no follow-up report was provided, the investigator had to provide justification. The adverse events were followed until they were either resolved or the investigator determined that the event was no longer clinically significant.

Statistical analysis. Eligible patients were randomly assigned at a 1:1 ratio to receive TJ-54 or control. After checking patient eligibility, randomization was carried out centrally at the data center using dynamic randomization with gender, performance status before surgery, type of malignancies and institution.

Assuming an incidence of delirium of 5\% in the TJ-54 group and $20 \%$ in the control group, a sample size of 88 for each group was estimated to have $\geq 80 \%$ power under a two-sided significance level of $10 \%$. Thus, to account for possible dropouts, a target sample size of 200 patients was required.

The risk ratios of the incidence of delirium between the groups and its $95 \%$ confidence interval (CI) were calculated. A risk ratio $<1$ indicated that TJ-54 was better than the control. Comparisons were made using the Chi-squared test. The baseline characteristics were compared using the Chi-squared test for categorical variables and the Wilcoxon test for continuous variables. The frequencies of adverse events were compared using the Fisher's exact test. All the P-values were two-sided. The statistical analyses were performed using the SAS software package for Windows, release 9.3 (SAS Institute, Cary, NC, USA).

\section{Results}

Patients. Of the patients receiving surgery for gastrointestinal or lung malignancy patients, 186 provided informed consent were randomized to either the TJ-54 $(n=93)$ or control $(n=93)$ group. A flow diagram of the participants' progress through the study protocol is shown in Fig. 1. The baseline demographics and disease characteristics of the per protocol set (PPS) population are shown in Table I. Male subjects comprised $64.5 \%$, and $35.5 \%$ of the subjects were female, and the median age was 77 years (range: $70-89$ years). The majority of patients $(90 \%)$ had histologically confirmed gastrointestinal malignancy, and $10 \%$ had histologically confirmed lung malignancy. There were no marked differences between the two PPS randomized groups.

Surgical details and postoperative course. The median amount of bleeding was significantly less in the TJ-54 group 
Table I. Patient characteristics of the TJ-54 and control groups.

\begin{tabular}{|c|c|c|c|}
\hline Factors & $\begin{array}{l}\text { Control } \\
(\mathrm{N}=93)\end{array}$ & $\begin{array}{c}\mathrm{TJ}-54 \\
(\mathrm{~N}=93)\end{array}$ & P-value \\
\hline $\operatorname{Sex}(\%)$ & & & 1.000 \\
\hline Male & $60(64.5)$ & $60(64.5)$ & \\
\hline Female & $33(35.5)$ & $33(35.5)$ & \\
\hline Age & & & 0.406 \\
\hline Median (range) & $76(70-89)$ & $77(70-88)$ & \\
\hline PS (\%) & & & 0.620 \\
\hline $0-1$ & $83(89.3)$ & $85(91.4)$ & \\
\hline 2 & $10(10.8)$ & $8(8.6)$ & \\
\hline Type of malignancy (\%) & & & 0.261 \\
\hline Gastric cancer & $48(51.6)$ & 39 (41.9) & \\
\hline Colorectal cancer & $36(38.7)$ & $35(37.6)$ & \\
\hline Lung cancer & $9(9.7)$ & $10(10.8)$ & \\
\hline MMSE score & & & 0.736 \\
\hline Median (range) & $29(9-30)$ & $29(16-30)$ & \\
\hline \multicolumn{4}{|l|}{ Comorbidity (\%) } \\
\hline Hypertension & $51(54.8)$ & $49(52.7)$ & \\
\hline COPD & $6(6.5)$ & $10(10.8)$ & \\
\hline Diabetes mellitus & $17(18.3)$ & $22(23.7)$ & \\
\hline
\end{tabular}

PS, performance status; MMSE, Mini-Mental State Examination; COPD, chronic obstructive pulmonary disease.

than in the control group $(\mathrm{P}=0.035)$ (Table II). The median duration of surgery was marginally significantly longer in the control group than in the TG-54 group $(\mathrm{P}=0.067)$. No marked differences were observed between the groups in terms of the postoperative course.

Incidence of delirium and postoperative course. The incidence of delirium was $6.5 \%$ (6 patients) in the TJ-54 group and $9.7 \%$ (9 patients) in the control group, and there was no significant difference between the two groups $(\mathrm{P}=0.471)$. Of note, the primary endpoint was not met in this study.

The subgroup analysis of the present study is shown in Fig. 2. Among the patients who were MMSE $\leq 26$, the incidence of postoperative delirium was $9.1 \%$ in the TJ-54 group and $26.9 \%$ in the control group [risk ratio: $0.338 ; 95 \% \mathrm{CI}$ (0.078-1.462), $\mathrm{P}=0.115]$, while among the patients who were MMSE $\geq 27$, the incidence of postoperative delirium was $6.8 \%$ in the TJ-54 group and $3.6 \%$ in the control group [risk ratio: $1.864 ; 95 \%$ CI $(0.356-9.778), \mathrm{P}=0.453]$. Thus, treatment with $\mathrm{TJ}-54$ may reduce the incidence of postoperative delirium compared with the control group.

Safety and postoperative course. Hematological, blood biochemistry and non-hematological toxicities were analyzed (Table III). The majority of these events were mild to moderate in severity and considered to be unrelated to the study drug. The length of the hospital stay was also similar between the TJ-54 group and the control group (16 vs. 15 days, $\mathrm{P}=0.867$ ).
Table II. Surgical details and postoperative course of the TJ-54 and control groups.

\begin{tabular}{|c|c|c|c|}
\hline Factors & $\begin{array}{l}\text { Control } \\
(\mathrm{N}=93)\end{array}$ & $\begin{array}{l}\mathrm{TJ}-54 \\
(\mathrm{~N}=93)\end{array}$ & P-value \\
\hline Operation time & & & 0.067 \\
\hline Median (range) & $\begin{array}{c}247 \mathrm{~min} \\
(50-59.49)\end{array}$ & $\begin{array}{l}222 \min \\
(83-482)\end{array}$ & \\
\hline Blood loss & & & 0.035 \\
\hline Median (range) & $\begin{array}{c}136 \mathrm{ml} \\
(5-31.00)\end{array}$ & $\begin{array}{c}67 \mathrm{ml} \\
(5-15.34)\end{array}$ & \\
\hline Type of surgery (\%) & & & 0.809 \\
\hline Gastrointestinal & $84(90.3)$ & $83(89.2)$ & \\
\hline Thoracic & $9(9.7)$ & $10(10.8)$ & \\
\hline Type of approach (\%) & & & 1.000 \\
\hline Conventional & $41(44.1)$ & $41(44.1)$ & \\
\hline $\begin{array}{l}\text { Laparoscopic or } \\
\text { thoracoscopic }\end{array}$ & $52(55.9)$ & $52(55.9)$ & \\
\hline First oral intake & & & 0.576 \\
\hline Median (range) & $\begin{array}{l}4 \text { day } \\
(2-69)\end{array}$ & $\begin{array}{l}4 \text { day } \\
(2-81)\end{array}$ & \\
\hline $\begin{array}{l}\text { Surgical } \\
\text { complications (\%) }\end{array}$ & & & 0.306 \\
\hline Yes & $23(24.7)$ & $26(28.0)$ & \\
\hline No & $70(75.3)$ & $67(72.0)$ & \\
\hline $\begin{array}{l}\text { Length of } \\
\text { hospital stay }\end{array}$ & & & 0.867 \\
\hline Median (range) & $\begin{array}{l}16 \text { day } \\
(7-101)\end{array}$ & $\begin{array}{l}15 \text { day } \\
(7-267)\end{array}$ & \\
\hline
\end{tabular}

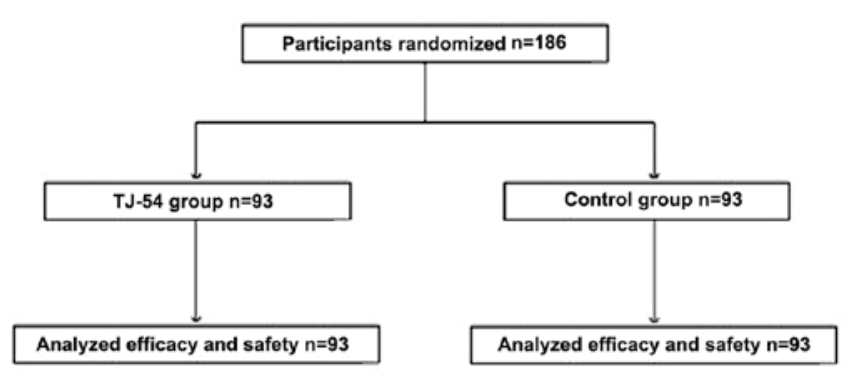

Figure 1. CONSORT diagram.

\section{Discussion}

This randomized trial is the first evaluation of the utility of TJ-54 for preventing and/or treating postoperative delirium in patients undergoing gastrointestinal or lung malignancy surgery in a randomized phase II trial. The primary aim of this study was to prove the effects of TJ-54 in reducing the incidence of postoperative delirium. The incidence of postoperative delirium was $6.5 \%$ in the TJ-14 group and $9.7 \%$ in the control group in the overall study population. Therefore, treatment with TJ-54 did not show any obvious efficacy 


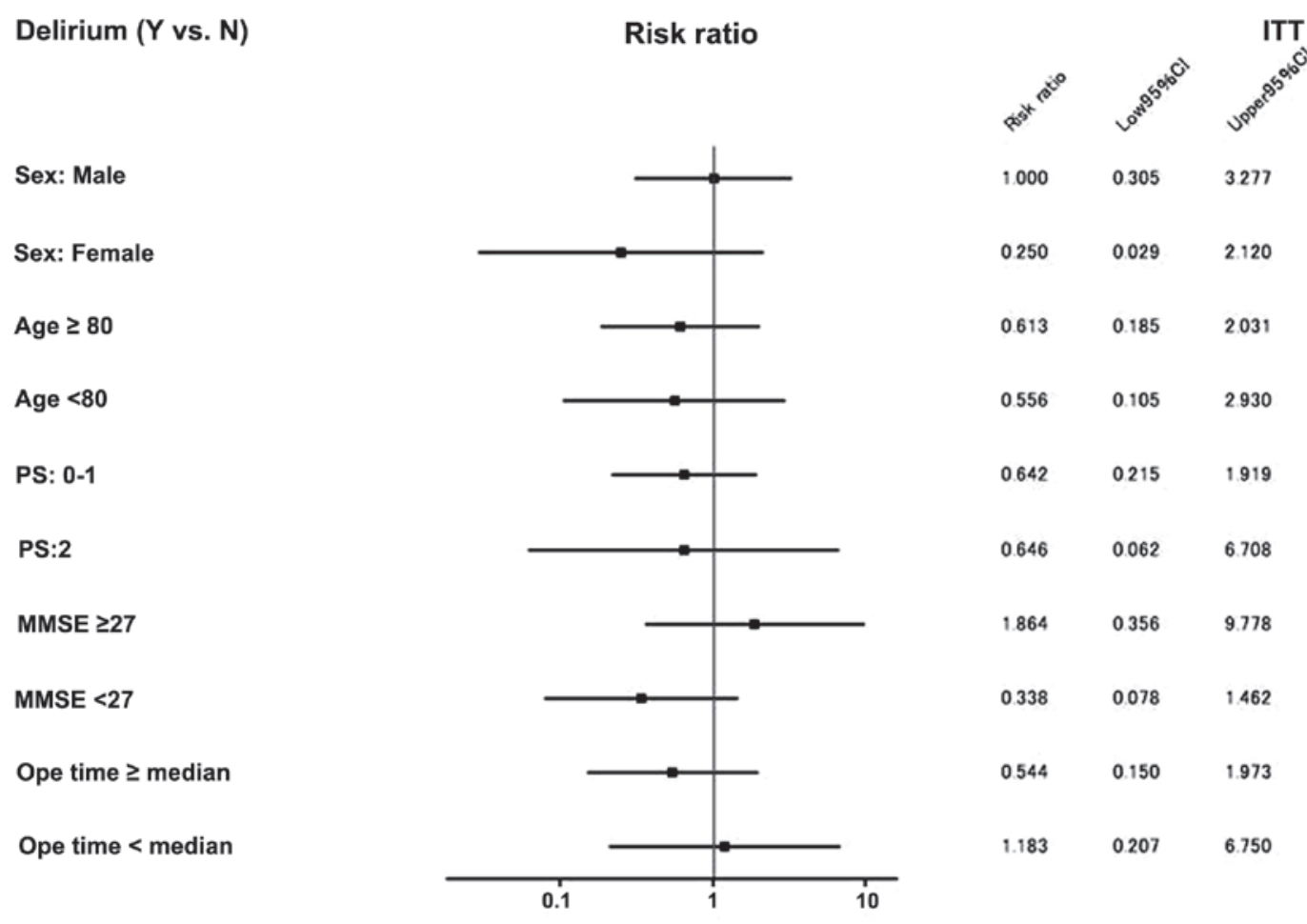

Figure 2. Subgroup analysis.

against postoperative delirium in patients receiving surgery for gastrointestinal and lung malignancy.

Several reasons may explain why this trial did not meet its primary objective. First, TJ-54 may not actually be able to prevent and/or treat postoperative delirium. Second, the incidence of expected postoperative delirium was not observed in the control arm in the present study. Previous findings have shown that the incidence of delirium after major non-cardiovascular surgery ranged from 13 to $50 \%(4,18,19)$. Given these data, we predicted an incidence of delirium of $20 \%$ in the control group. However, the present results showed that the incidence of delirium was only $9.7 \%$ in the control group. This discrepancy may be due to the following: First, the rate of postoperative delirium may have been underestimated. In the present study, the physicians checked the mental condition of all the patients at their bedside during the perioperative period and recorded the psychiatric symptoms. However, the physicians were able to detect only hyperactive delirium and could not detect hypoactive delirium, which is often misdiagnosed as depression or fatigue (7). Second, the surgical stress, such as blood loss and operative time, was lower in our study than in previous reports. Risk factors for postoperative delirium that have been reported include increased blood loss and increased operative time $(20,21)$. However, the median blood loss in our study was 67 and $136 \mathrm{ml}$, and the median operative time was 222 and $247 \mathrm{~min}$, which was lower than in previous reports. Furthermore, $50 \%$ of the patients received laparoscopic or thoracspoic surgery. Generally, the surgical stresses are lower for laparoscopic or thoracspoic surgery than conventional procedures $(22,23)$.

One important limitation of the present study is the lack of information for the preoperative nutrition status. Some of the patients with gastrointestinal cancer may lose their weight
Table III. Hematological and biochemical toxicities greater than Grade 2 or more observed during treatment.

\begin{tabular}{lccc}
\hline Toxicity type & $\begin{array}{c}\text { Contoral } \\
(\mathrm{N}=93)\end{array}$ & $\begin{array}{c}\mathrm{TJ}-54 \\
(\mathrm{~N}=93)\end{array}$ & P-value \\
\hline $\begin{array}{l}\text { Hematological } \\
\text { toxicity (\%) }\end{array}$ & & & \\
Leucopenia & $0(0)$ & $0(0)$ & - \\
Neutropenia & $0(0)$ & $0(0)$ & - \\
Hemoglobin & $0(0)$ & $0(0)$ & - \\
Platelet & $0(0)$ & $0(0)$ & - \\
T-Bil & $3(3.2)$ & $1(1.1)$ & 0.312 \\
AST & $15(16.2)$ & $8(8.6)$ & 0.119 \\
ALT & $10(10.8)$ & $6(6.5)$ & 0.296
\end{tabular}

Non-hematological

toxicity $(\%)$

$\begin{array}{lll}\text { Anorexia } & 0(0) & 0(0) \\ \text { Nausea } & 0(0) & 0(0) \\ \text { Vomiting } & 0(0) & 0(0) \\ \text { Diarrhea } & 0(0) & 0(0) \\ \text { Constipation } & 0(0) & 0(0) \\ \text { Peripheral neuropathy } & 0(0) & 0(0) \\ \text { Lassitude } & 0(0) & 0(0) \\ \text { Skin reaction } & 0(0) & 0(0) \\ \text { Dyspepsia } & 0(0) & 0(0) \\ \text { Edema } & 0(0) & 0(0) \\ \text { Change in PS } & 0(0) & 0(0)\end{array}$

T-Bil, total-bilirubin; AST, aspartate aminotransferase; ALT, alanine aminotransferase. 
before operation and nutritional status is potentially poor. Nutrition status, such as BMI or serum albumin, could affect the results. Thus, further studies taking nutrition status into consideration are necessary.

However, a borderline significant difference was observed between the two groups among patients who were MMSE $\leq 26$ : the incidence of postoperative delirium was 9.1\% in the TJ-54 group and $26.9 \%$ in the control group (risk ratio: $0.338 ; 95 \%$ CI [0.078-1.462], $\mathrm{P}=0.453)$. By contrast, among the patients who were MMSE $\geq 27$, the incidence of postoperative delirium was $6.8 \%$ in the TJ-54 group and $3.6 \%$ in the control group [risk ratio: $1.864 ; 95 \%$ CI $(0.356-9.778), \mathrm{P}=0.453$ ]. Treatment with TJ-54 reduced the incidence of postoperative delirium compared with the control group. Among the patients who were MMSE $\leq 26$, an obvious reduction in the risk of delirium (hazard ratio 0.338 ) was demonstrated. As mentioned above, it was previously reported that TJ-54 exerts slight agonistic effects on 5-HT 1A receptors, antagonistic effects on 5-HT $2 \mathrm{~A}$ receptors, and protective effects against glutamate-induced excitatory neurotoxicity by amelioration of astrocyte dysfunction. Further studies are needed to clarify the exact mechanisms underlying these observations.

In conclusion, this study showed no beneficial effects of TJ-54 in reducing the incidence of postoperative delirium as the primary endpoint. However, among patients who were MMSE $\leq 26$, an obvious reduction in the risk of postoperative delirium (risk ratio: 0.338) was demonstrated. Further analyses may lead to a better interpretation of the study results by examining subgroups that will particularly benefit from TJ-54 treatment. A more definitive design in a future trial of TJ-54 for postoperative delirium is needed.

\section{Acknowledgements}

The authors would like to thank Professor Satoshi Morita and Ms. Maho Sato for excellent data management in this study. The authors would like to express their deepest appreciation to Yukihiro Ozawa, Miura City Hospital, Kimiatsu Hasuo, Japanese Red Cross Hadano Hospital, Hiroyasu Tanabe, International University of Health and Welfare Atami Hospital, Katsuya Yoneyama, Kanagawa Prefectural Ashigarakami Hospital for cooperation in this study.

\section{References}

1. Torre LA, Bray F, Siegel RL, Ferlay J, Lortet-Tieulent J and Jemal A: Global cancer statistics, 2012. CA Cancer J Clin 65: 87-108, 2015.

2. Sasako M, Sano T, Yamamoto S, Kurokawa Y, Nashimoto A, Kurita A, Hiratsuka M, Tsujinaka T, Kinoshita T, Arai K, et al: D2 lymphadenectomy alone or with para-aortic nodal dissection for gastric cancer. N Engl J Med 359: 453-462, 2008.

3. Yeo CJ, Cameron JL, Lillemoe KD, Sohn TA, Campbell KA, Sauter PK, Coleman J, Abrams RA and Hruban RH: Pancreaticoduodenectomy with or without distal gastrectomy and extended retroperitoneal lymphadenectomy for periampullary adenocarcinoma, part 2: Randomized controlled trial evaluating survival, morbidity, and mortality. Ann Surg 236: 355-368, 2002.

4. Yamamoto S, Inomata M, Katayama H, Mizusawa J, Etoh T, Konishi F, Sugihara K, Watanabe M, Moriya Y and Kitano S Japan Clinical Oncology Group Colorectal Cancer Study Group: Short-term surgical outcomes from a randomized controlled trial to evaluate laparoscopic and open D3 dissection for stage II/III colon cancer: Japan clinical oncology group study JCOG 0404 Ann Surg 260: 23-30, 2014.
5. Inouye SK, Westendorp RG and Saczynski JS: Delirium in elderly people. Lancet 383: 911-922, 2014.

6. Marcantonio ER, Goldman L, Mangione CM, Ludwig LE, Muraca B, Haslauer CM, Donaldson MC, Whittemore AD, Sugarbaker DJ, Poss R, et al: A clinical prediction rule for delirium after elective noncardiac surgery. JAMA 271: 134-139, 1994.

7. Takeuchi M, Takeuchi H, Fujisawa D, Miyajima K, Yoshimura K Hashiguchi S, Ozawa S, Ando N, Shirahase J, Kitagawa Y and Mimura M: Incidence and risk factors of postoperative delirium in patients with esophageal cancer. Ann Surg Oncol 19: 3963-3970, 2012.

8. Francis J, Martin D and Kapoor WN: A prospective study of delirium in hospitalized elderly. JAMA 263: 1097-1101, 1990

9. Inouye SK, van Dyck CH, Alessi CA, Balkin S, Siegal AP and Horwitz RI: Clarifying confusion: The confusion assessment method. A new method for detection of delirium. Ann Intern Med 113: 941-948, 1990.

10. Furukawa K, Tomita N, Uematsu D, Okahara K, Shimada H, Ikeda M, Matsui T, Kozaki K, Fujii M, Ogawa T, et al: Randomized double-blind placebo-controlled multicenter trial of Yokukansan for neuropsychiatric symptoms in Alzheimer's disease. Geriatr Gerontol Int 17: 211-218, 2017.

11. Ueki T, Mizoguchi K, Yamaguchi T, Nishi A, Ikarashi Y, Hattori T and Kase Y: Yokukansan increases 5-HT1A receptors in the prefrontal cortex and enhances 5-HT1A receptor agonist-induced behavioral responses in socially isolated mice. Evid Based Complement Alternat Med 2015: 726471, 2015.

12. Okamoto H, Iyo M, Ueda K, Han C, Hirasaki Y and Namiki T: Yokukan-san: A review of the evidence for use of this Kampo herbal formula in dementia and psychiatric conditions. Neuropsychiatr Dis Treat 10: 1727-1742, 2014.

13. Takeda $\mathrm{A}$, Itoh $\mathrm{H}$, Tamano $\mathrm{H}$, Yuzurihara $\mathrm{M}$ and $\mathrm{Oku} \mathrm{N}$ : Suppressive effect of Yokukansan on excessive release of glutamate and aspartate in the hippocampus of zinc-deficient rats. Nutr Neurosci 11: 41-46, 2008.

14. Takeda A, Tamano H, Itoh $\mathrm{H}$ and Oku N: Attenuation of abnormal glutamate release in zinc deficiency by zinc and yokukansan. Neurochem Int 53: 230-235, 2008.

15. Kawakami Z, Kanno H, Ueki T, Terawaki K, Tabuchi M, Ikarashi Y and Kase Y: Neuroprotective effects of yokukansan, a traditional Japanese medicine, on glutamate-mediated excitotoxicity in cultured cells. Neuroscience 159: 1397-1407, 2009.

16. Arai YC, Kawanishi J, Sakakima Y, Sueoka S, Ito A, Tawada Y, Maruyama Y, Banno S, Takayama H, Nishihara M, et al: The effect of the kampo medicine yokukansan on preoperative anxiety and sedation levels. Evid Based Complement Alternat Med 2014: 965045, 2014.

17. American Psychiatric Association: Diagnostic and statistical manual of mental disorders. 4th edition. American Psychiatric Association, Washington, DC, 1994.

18. Edlund A, Lundström M, Lundström G, Hedqvist B and Gustafson Y: Clinical profile of delirium in patients treated for femoral neck fractures. Dement Geriatr Cogn Disord 10: 325-329, 1999.

19. Lee KH, Ha YC, Lee YK, Kang H and Koo KH: Frequency, risk factors, and prognosis of prolonged delirium in elderly patients after hip fracture surgery. Clin Orthop Relat Res 469: 2612-2620, 2011.

20. Raats JW, Steunenberg SL, de Lange DC and van der Laan L: Risk factors of post-operative delirium after elective vascular surgery in the elderly: A systematic review. Int J Surg 35: 1-6, 2016.

21. Yamagata K, Onizawa K, Yusa H, Wakatsuki T, Yanagawa T and Yoshida H: Risk factors for postoperative delirium in patients undergoing head and neck cancer surgery. Int J Oral Maxillofac Surg 34: 33-36, 2005.

22. Zeng YK, Yang ZL, Peng JS, Lin HS and Cai L: Laparoscopyassisted versus open distal gastrectomy for early gastric cancer: Evidence from randomized and nonrandomized clinical trials. Ann Surg 256: 39-52, 2012.

23. Adachi Y, Shiraishi N, Shiromizu A, Bandoh T, Aramaki M and Kitano S: Laparoscopy-assisted Billroth I gastrectomy compared with conventional open gastrectomy. Arch Surg 135: 806-810, 2000 . 